\title{
Increased exhaled nitric oxide on days with high outdoor air pollution is of endogenous origin
}

\author{
P.A. Steerenberg*, J.B. Snelder*, P.H. Fischer**, J.G. Vos*, H. van Loveren*, J.G.C. van \\ Amsterdam $^{+}$
}

\begin{abstract}
Increased exhaled nitric oxide on days with high outdoor air pollution is of endogenous origin. P.A. Steerenberg, J.B. Snelder, P.H. Fischer, J.G. Vos, H. van Loveren, J.G.C. van Amsterdam. (C) ERS Journals Ltd 1999.

ABSTRACT: The aim of this study was to assess the effect of outdoor air pollution on exhaled levels of endogenously released nitric oxide.

To exclude bias from exogenous NO in the recovered exhaled air (residual NO or NO in dead volume) an experimental design was used that sampled NO of endogenous origin only. The validity of the presented experimental design was established in experiments where subjects were exposed to high levels of exogenous NO (cigarette smoke or $480 \mu \mathrm{g} \cdot \mathrm{m}^{-3}$ synthetic NO). Subsequent $1 \mathrm{~min}$ breathing and a final inhalation of NO-free air proved to be sufficient to attain pre-exposure values.

Using the presented method detecting only endogenous NO in exhaled air, 18 subjects were sampled on 4 seperate days with different levels of outdoor air pollution (read as an ambient NO level of $4,30,138$ and $246 \mu \mathrm{g} \cdot \mathrm{m}^{-3}$ ). On the 2 days with highest outdoor air pollution, exhaled NO was significantly $(p<0.001)$ increased $(67-78 \%)$ above the mean baseline value assessed on 4 days with virtually no outdoor air pollution.

In conclusion, the level of endogenous nitric oxide in exhaled air is increased on days with high outdoor air pollution. The physiological implications of this findings need to be investigated further.
\end{abstract}

Eur Respir J 1999; 13: 334-337.
* Laboratory for Pathology and Immunobiology, **Dept of Chronic Diseases and Environmental Epidemiology, and ${ }^{+}$Laboratory of Health Effects Research, National Institute of Public Health and the Environment, Bilthoven, The Netherlands.

\section{Correspondence: P.A. Steerenberg}

Laboratory for Pathology and Immunobiology

National Institute of Public Health and the Environment

P.O. Box 1

3720 BA Bilthoven

The Netherlands

Fax: 31302744437

Keywords: Air pollution exhaled nitric oxide nitric oxide

Received: April 161998 Accepted after revision July 271998
Epidemiological studies have reported an association between air pollution and an increased incidence of respiratory symptoms, increased hospitalization for respiratory diseases, decreased pulmonary function, and premature mortality $[1,2]$.

Endogenous nitric oxide is derived from L-arginine, a reaction catalysed by the enzyme NO synthase (NOS). NOS appears to exist in multiple isoforms, i.e. constitutive NOS (cNOS) and inducible NOS (iNOS) responsible for the production of nanomolar and micromolar quantities of NO, respectively. iNOS is induced by various pro-inflammatory cytokines such as tumour necrosis factor (TNF)$\alpha$, interleukin (IL)- $1 \beta$ and interferon (IFN)- $\gamma$ [3]. There is increasing evidence that cNOS-dependent NO production by epithelial cells plays a key role in airway physiology. NO retains bronchodilatory properties [4], suggesting that increased endogenous NO production is beneficial while iNOS-dependent NO production is implicated in airway diseases such as upper respiratory tract infections, asthma, and allergy [3, 5-7].

The higher the level of NO inhaled, the more remains to be exhaled. Despite the rapid absorption of previously inhaled exogenous NO by the respiratory tissue [8, 9], residual NO and environmental NO in the dead volume may still contaminate the sample of exhaled air. As a result, incorrectly high values of exhaled endogenously produced NO are obtained when exhaled air is sampled on days with high environmental NO. Indeed, in a pilot study a positive association $(\mathrm{p}<0.001)$ was found between the level of outdoor air pollution and exhaled NO in 35 volunteers, confirming recent data ([10] and personal communication R. Jöbsis, Sophia Children's Hospital, Rotterdam, the Netherlands). As reviewed by KHARITONOv et al. [11], however others did not find such an association [12-17].

In the present study the effect of outdoor air pollution on exhaled levels of endogenous NO was determined in control subjects. For this purpose a valid experimental design was initially developed to exclude any contribution of inhaled environmental NO to the value of exhaled endogenous NO.

\section{Materials and methods}

\section{Study subjects}

The study population sample consisted of 18 nonsmoking (12 males and six females, aged 25-50 yrs) and four smoking subjects (four males, aged 22-24 yrs). Subjects had no current medical problems and received no oral or inhaled medication (steroids or bronchodilators). All subjects gave written consent to participate in the study.

\section{Experimental design}

Outdoor air was sampled by a permissible air sampling pump (model P-200; Dupont de Nemours \& Company, Wilmington, DE, USA) and $250 \mathrm{~mL}$ air was collected in an aluminium foil air bag. Outdoor air pollution was read 
by the concentration of ambient NO in the outdoor air sample.

The concentration of NO in the exhaled air depends on its flow and pressure [18]. Sampling of exhaled air was, therefore, carried out with a blow pipe (sampling device) equipped with an $18 \mathrm{G}$ needle as flow restrictor and a manometer connected to indicator lamps. Guided by the indicator lamps subjects exhaled air in a reproducible way at the desired flow rate of $500 \mathrm{~mL} \cdot \mathrm{min}^{-1}$ at a pressure of 20 $\mathrm{cmH}_{2} \mathrm{O}$. The applied pressure ensured the closure of the soft palate and excludes diffusion of NO from nasal sources [11]. Volunteers inhaled deeply and immediately exhaled $250 \mathrm{~mL}$ (during $30 \mathrm{~s}$ ) via the sampling device into a 500-mL, NO-impermeable aluminium foil air bag (Mylar balloon; ABC Ballonnen, Zeist, the Netherlands). The exhaled volume was always $250 \mathrm{~mL}$. Exhaled air was either collected directly or was preceded by breathing clean air for 1-2 min with a final inhalation of clean air. Clean air (medical inhalation air containing $<0.1 \mu \mathrm{g} \cdot \mathrm{m}^{-3} \mathrm{NO}$; HockLoos, Dieren, the Netherlands) was delivered from the gas cylinder via a wide-bore silicone tube to a silicone mouth/ face cap (adult medium/large two-way NRBV, Y-shape; Hans Rudolph, Kansas City, MO, USA).

The contribution of inhaled exogenous NO to the level of expired NO was assessed in four subjects exposed to high concentrations of exogenous NO (cigarette smoke containing $6,000-25,000 \mu \mathrm{g} \cdot \mathrm{m}^{-3} \mathrm{NO}$ or $480 \mu \mathrm{g} \cdot \mathrm{m}^{-3}$ synthetic NO for $1 \mathrm{~min}$ ). Exhaled air was sampled before, during and after smoking 1 cigarette. Immediately after stopping smoking subjects started to breathe clean air for $1 \mathrm{~min}$, then deeply inhaled clean air and exhaled $250 \mathrm{~mL}$ air as described above. This procedure was immediately repeated twice using additional clean air breathing for 2 min. As such, three exhaled air samples were obtained within $6.5 \mathrm{~min}$ after stopping smoking. During smoking no clean air was used.

The effect of outdoor air pollution on the level of expired NO was studied in 18 subjects by sampling exhaled air, as described above, in the morning (09:00-10:00 h) on 4 days with negligible air pollution $\left(3.6 \pm 1 \mu \mathrm{g} \cdot \mathrm{m}^{-3}\right.$ ambient NO) and 4 days with different levels of air pollution (4, 30,138 and $246 \mu \mathrm{g} \cdot \mathrm{m}^{-3}$ ambient NO). Two samples of 250 $\mathrm{mL}$ exhaled air were recovered within $2 \mathrm{~min}$. The first sample was obtained before and the second sample after 1 min breathing clean air. The third sample was recovered after an additional 2 min breathing clean air.

\section{Assay of nitric oxide}

A rapid-response chemiluminescence analyser (Sievers $280 \mathrm{~B}$, Boulder, CO, USA) with a response time $<200 \mathrm{~ms}$ was used to determine the concentration of exhaled NO. The analyser sample flow rate was kept constant at 200 $\mathrm{mL} \cdot \mathrm{min}^{-1}$. NO calibration gas was diluted with clean air to a concentration of $480 \mu \mathrm{g} \cdot \mathrm{m}^{-3} \mathrm{NO}$. In the aluminium foil bag NO concentrations remain constant for at least $48 \mathrm{~h}$. Using this procedure low exhaled NO levels $\left(1.2-6 \mu \mathrm{g} \cdot \mathrm{m}^{-3}\right)$ could be determined in a reproducible manner.

\section{Statistical analysis}

Subjects showed a large interindividual variation, which hindered calculations of mean levels of exhaled $\mathrm{NO}$ on specific days of testing. The baseline exhaled NO value of each subject is the mean of exhaled NO values obtained on 4 days with negligible air pollution $\left(1.2-6 \mu \mathrm{g} \cdot \mathrm{m}^{-3} \mathrm{am}-\right.$ bient NO). Individual exhaled NO values of the subjects obtained on the 4 days with different levels of outdoor air pollution were expressed as a percentage of their baseline value. For the separate days the means of these values were calculated.

One-way analysis of variance (ANOVA) was used to determine the effect of outdoor air pollution on endogenously produced NO and statistical differences were evaluated using the Student's t-test.

Statistical significance was assumed at $\mathrm{p}<0.05$.

\section{Results}

To determine the effect of outdoor air pollution containing ambient $\mathrm{NO}$ on exhaled levels of endogenous $\mathrm{NO}$ an experimental design was developed to exclude the eventual contribution of residual $\mathrm{NO}$ and ambient $\mathrm{NO}$ in the dead volume to the value of exhaled endogenous NO.

Figure 1 shows the concentrations of NO in exhaled air of four volunteers before, during and after smoking one cigarette. Upon stopping smoking and 1 min breathing clean air, exhaled NO levels returned to the values obtained before exposure to the high dose of exogenous NO. In a separate experiment (data not shown) volunteers were exposed for $1 \mathrm{~min}$ to $480 \mu \mathrm{g} \cdot \mathrm{m}^{-3}$ synthetic NO. Again, after 1 min breathing clean air, the NO value in exhaled air had returned to the pre-exposure level. Additional clean air breathing (once or twice for $2 \mathrm{~min}$ ) did not further decrease the exhaled NO level, as such air samples contain no residual exogenous NO. These results suggested that on days of high environmental NO, exhaled NO levels obtained after 1 min breathing clean air reflect exhaled amounts of endogenous NO only.

Figure 2 shows the exhaled NO values of 18 volunteers before and after 1 min breathing clean air on 4 days with different levels of outdoor air pollution (read as ambient

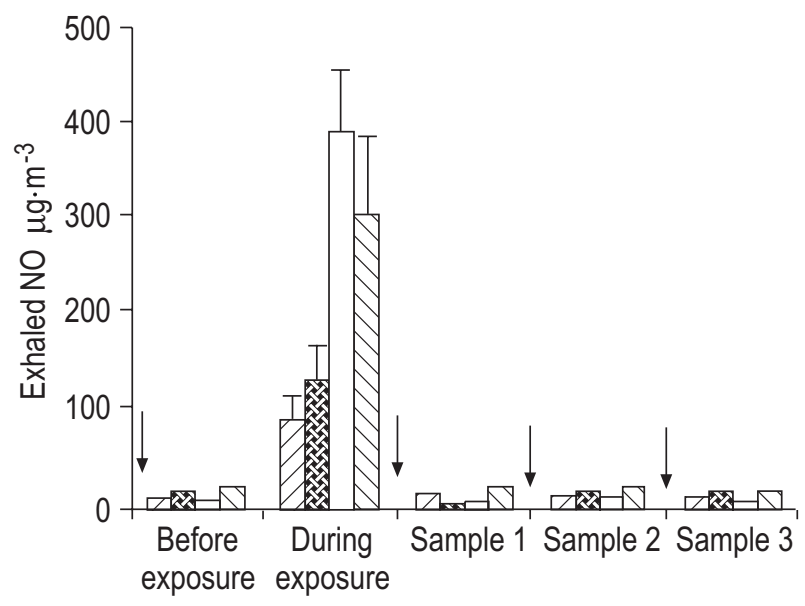

Fig. 1. - Levels of exhaled nitric oxide (expressed as means \pm SEM) determined before, during and after cigarette smoking in four regular smokers. $\mathbb{Z}$ : subjects no. 1 ; $:$ subject no. $2 ; \square:$ subject no. $3 ; \mathbb{\mathbb { N }}$ : subject no. 4. Cigarette smoke contained $6,000-25,000 \mu \mathrm{g} \cdot \mathrm{m}^{-3} \mathrm{NO}$. Arrows indicate $1 \mathrm{~min}$ breathing and a final inhalation of clean air prior to sampling exhaled air. The two final samples were obtained following 2 min breathing and a final inhalation of clean air. The entire postexposure sampling procedure took $6.5 \mathrm{~min}$. 


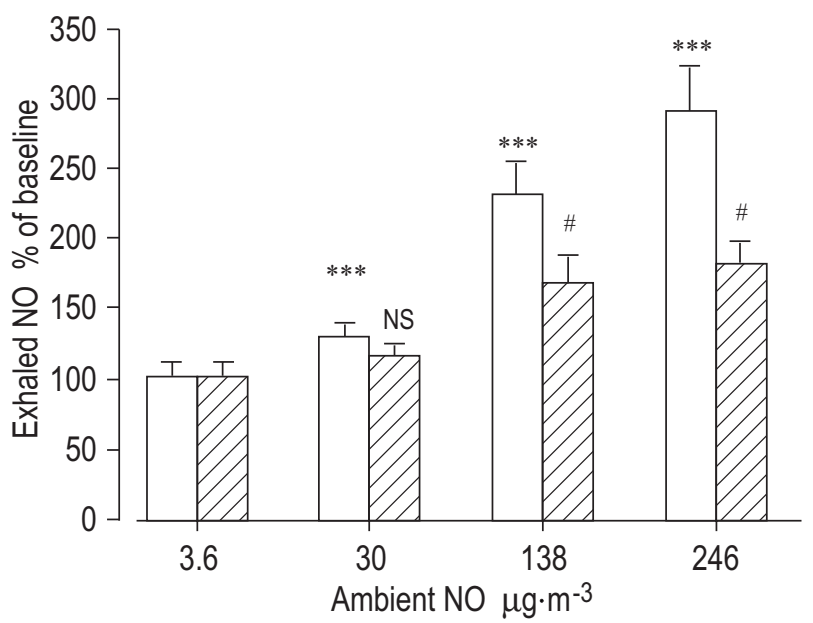

Fig. 2. - Levels of exhaled nitric oxide (means \pm SEM) on four days with different levels of outdoor air pollution. Air samples were collected before (first sample, $\square$ ) and after 1 min breathing and a final inhalation of clean air $(\mathbb{Z})$. Outdoor air pollution was read as the ambient NO level, which amounted to $4,30,138$ and $246 \mu \mathrm{g} \cdot \mathrm{m}^{-3}$. Individual exhaled NO values were expressed as a percentage of their baseline value and the averaged value of the group on separate days was calculated. $* * *$ : $\mathrm{p}<0.001$, compared with respective exhaled NO level on the day with negligible outdoor air pollution $\left(3.6 \mu \mathrm{g} \cdot \mathrm{m}^{-3}\right.$ ambient $\left.\mathrm{NO}\right)$; ${ }^{\#}: \mathrm{p}<0.001$, compared with first sample.

NO concentrations of $4,30,138$ and $246 \mu \mathrm{g} \cdot \mathrm{m}^{-3}$ ) and shows that exhaled endogenous NO was significantly increased on days with increased air pollution. Ambient NO contaminated the first sample (taken before $1 \mathrm{~min}$ breathing and a final inhalation of clean air) and added substantially to the actual level of exhaled endogenous NO (obtained after breathing clean air). One minute breathing and a final inhalation of clean air before sampling reduced the exhaled NO level by $0 \%, 12 \pm 5 \%, 27 \pm 6 \%$ and $38 \pm 5 \%$ (mean \pm SEM), respectively for the 4 ambient NO concentrations. On the 2 days with the highest level of outdoor air pollution (ambient NO concentration of 138 and $246 \mu \mathrm{g} \cdot \mathrm{m}^{-3}$ ) the level of the remaining part of exhaled NO (i.e. second sample), representing exhaled endogenous NO, was still increased significantly $(+62 \pm 18 \%$ and $+73 \pm 18 \%$, means \pm SEM) compared with the day with virtually no air pollution $(\mathrm{p}<0.001)$. Finally, no significant difference was observed between the level of NO in exhaled air obtained after 1 min versus 3 min breathing clean air (data not shown).

\section{Discussion}

The results showed that endogenous NO levels in exhaled air were increased on days with a high level of outdoor air pollution, suggesting the stimulation of NO release by atmospheric contaminants.

The higher the level of NO inhaled, the more remains to be exhaled. Sampling exhaled air on days with high outdoor air pollution will therefore, result in overestimated values of exhaled endogenous NO ([10] and personal communication R. Jöbsis, Sophia Children's Hospital, Rotterdam, the Netherlands) because the exhaled air sample may be contaminated with environmental NO either by residual NO or by ambient NO in the dead volume.
NO diffuses through biomembranes even more rapidly than oxygen. Despite the rapid absorption of previously inhaled exogenous NO by the respiratory tissue $[8,9]$, residual exogenous $\mathrm{NO}$ and environmental $\mathrm{NO}$ in the dead volume may still contaminate the sample of exhaled air. To exclude both routes of contamination a procedure was introduced consisting of breathing clean air for $1 \mathrm{~min}$ followed by a final inhalation of clean air prior to sampling exhaled air.

Results obtained from experiments performed in subjects exposed to high levels of exogenous NO (cigarette smoke or $480 \mu \mathrm{g} \cdot \mathrm{m}^{-3}$ synthetic NO) confirmed that subsequent one-minute breathing (and a final inhalation of) clean air prior to sampling was sufficient to exclude contamination of samples with residual exogenous NO (fig. 1). Breathing clean air for more than $1 \mathrm{~min}$ did not further decrease exhaled NO (no significant difference in exhaled NO values obtained after 1 and 3 min breathing clean air). Thus, using the present approach only endogenously released NO was exhaled and collected in the sample bag. Therefore, an increase in its value reflected increased endogenous NO release and was not related, at least not directly, to increased ambient NO level.

In earlier studies no positive association between exposure to high levels of NO (experimental NO, cigarette smoke or ambient NO) and the exhaled NO level was observed [12, 14-16]; reviewed in [11]. This may be due to the 15-min time interval between the inhalation of exogenous NO and sampling air, allowing full absorption of NO [13], the introduction of a short (10-15 s) breathhold manoeuvre $[12,19]$ or measurement at relatively low levels of outdoor air pollution [12, 17].

Figure 2 shows that $1 \mathrm{~min}$ breathing and a final inhalation of clean air reduced the level of exhaled NO by $12 \pm$ $5 \%$ to $38 \pm 5 \%$ (mean \pm SEM). The remaining part of exhaled NO, being of endogenous origin, was still significantly higher $(+62 \pm 18 \%$ and $+73 \pm 18 \%$, means \pm SEM $)$ on the 2 days with the highest levels of outdor air pollution than on the day with virtually no air pollution. This important finding suggests that one or several components present in outdoor air pollution are responsible for the increased release of NO from the pulmonary tissue. There was a notable interindividual variation in exhaled NO among the subjects. For instance on a day with negligible ambient NO $\left(3.6 \mu \mathrm{g} \cdot \mathrm{m}^{-3}\right)$ the exhaled NO value ranged $9-120$ $\mu \mathrm{g} \cdot \mathrm{m}^{-3}$. The reason for this variation remains to be established but in this small sample seems not to be related to age, sex, body weight or height. Further studies in larger populations would be required to elucidate the basis of this interindividual variation.

It is of interest to identify the component(s) in the polluted ambient air that are responsible for the increase in exhaled endogenous NO. NO itself is not a likely candidate for two reasons. Firstly, based on the principle of product inhibition, decreased NO production would be expected. Secondly, cigarette smokers who are regularly exposed to high levels of $\mathrm{NO}$ exhale lower concentrations of NO than nonsmokers $[13,20,21]$. Another candidate that might be responsible for the increase in exhaled endogenous NO is diesel exhaust particles (DEP), which have been reported to affect the exhaled NO level. The results on NO release by DEP are, however, not very consistent. MuTo et al. [22] showed that DEP may reduce the activity of NO synthase in vitro, while SAGAI and ICHINOSE [23] 
observed an increase in the NO concentration of exhaled air in mice following exposure to DEP.

The physiological consequences of increased exhaled levels of endogenously produced NO on days with high outdoor air pollution remain to be elucidated. In physiological concentrations NO possesses vasodilatory and bronchodilatory activity and is as such, used clinically in the treatment of pulmonary hypertension [24] and acute respiratory distress syndrome [25]. However, NO may also increase plasma exudation in the airways, suggesting its involvement in the orchestration of the eosinophilic inflammation that characterizes asthma $[3,5,7,26]$. Whether the observed increase in endogenous exhaled NO reflects an actual inflammatory response or NO production by bronchial epithelial cells is the subject of further study.

In conclusion, using an appropriate experimental design to determine the levels of exhaled endogenous nitric oxide, this study showed that the level of endogenous nitric oxide in exhaled air is increased on days with high outdoor air pollution, suggesting the stimulation of nitric oxide by atmospheric contaminants. Finally, the value of exhaled nitric oxide could be used as a biomonitor of the health effects of outdoor air pollution in epidemiological studies.
8. Ewetz L. Absorption and metabolic fate of nitrogen oxides. Scand J Work Environ Health 1993; 19: Suppl. 2, 21-27.

9. Vanderkooi JM, Wright WW, Erecinska M. Nitric oxide diffusion coefficients in solutions, proteins and membranes determined by phosphorescence. Biochim Biophys Acta 1994; 1207: 249-254.

10. Baraldi E, Azzolin N, Dario C, et al. Effect of atmospheric nitric oxide (NO) on measurements of exhaled NO in asthmatic children. Pediatr Pulmonol 1998; 26: 30-34.

11. Kharitonov S, Alving K, Barnes PJ. Exhaled and nasal nitric oxide measurements: recommendations. The European Respiratory Society Task Force. Eur Respir J 1997; 10: 1683-1693.

12. Kharitonov SA, Yates D, Robbins RA, et al. Increased nitric oxide in exhaled air of asthmatic patients. Lancet 1994; 343: 133-135.

13. Kharitonov SA, Robbins RA, Yates D, et al. Acute and chronic effects of cigarette smoking on exhaled nitric oxide. Am J Respir Crit Care Med 1995; 152: 609-612.

14. Kimberly B, Nejadnik B, Giraud GD, et al. Nasal contribution to exhaled nitric oxide at rest and during breathholding in humans. Am J Respir Crit Care Med 1996; 153: 829-836.

15. Massaro AF, Gaston B, Kita D, et al. Expired nitric oxide levels during treatment of acute asthma. Am J Respir Crit Care Med 1995; 152: 800-803.

16. Robbins RA, Floreani AA, Von Essen SG, et al. Measurement of exhaled nitric oxide by three different techniques. Am J Respir Crit Care Med 1996; 153: 1631-1635.

17. Borland C, Cox Y, Higenbottam T. Measurement of exhaled nitric oxide in man. Thorax 1993; 48: 1160-1162.

18. Silkoff PE, MeClean PA, Slutsky AS, et al. Marked flowdependence of exhaled nitric oxide using a new technique to exclude nasal nitric oxide. Am J Respir Crit Care Med 1997; 155: 260-267.

19. Robbins RA, Floreani AA, Von Essen SG, et al. Measurement of exhaled nitric oxide by three different techniques. Am J Respir Crit Care Med 1996; 153: 1631-1635.

20. Hill GE, Ruggeroli A, Pohorecki R, et al. Cigarette smoking reduces endogenous airway nitric oxide production during cardiopulmonary bypass in humans. Anesth Analg 1995; 81: 170-172.

21. Persson MG, Zetterstrom O, Agrenius V, et al. Singlebreath nitric oxide measurements in asthmatic patients and smokers. Lancet 1994; 343: 146-147.

22. Muto E, Hayashi T, Yamada K, et al. Endothelial-constitutive nitric oxide synthase exists in airways and diesel exhaust particles inhibit the effect of nitric oxide. Life Sci 1996; 59: 1563-1570.

23. Sagai M, Ichinose T. Role of nitric oxide in asthma-like symptoms induced by diesel exhaust particles in mice. Nippon Kyobu Shikkan Gakkai Zasshi 1995; 33: Suppl., 212-217.

24. Frostell C, Fratacci MD, Wain JC, et al. Inhaled nitric oxide. A selective pulmonary vasodilator reversing hypoxic pulmonary vasoconstriction. Circulation 1991; 83: 20382047.

25. Rossaint R, Falke KJ, Lopez F, et al. Inhaled nitric oxide for the adult respiratory distress syndrome. $N$ Engl $\mathrm{J} \mathrm{Med}$ 1993; 328: 399-405.

26. Barnes PJ, Liew FY. Nitric oxide and asthmatic inflammation. Immunol Today 1995; 16: 128-130. 